\title{
Intracranial stimulation and natural reward: Differential effects of trial spacing
}

C. R. GALLISTEL

UNIVERSITY OF PENNSYLVANIA, PHLADELPHIA

Rats rewarded with intracranial stimulation (ICS) in a runway ran faster after a decrease in intertrial interval and slower after an increase. The effect was not found in rats rewarded with water under highly similar conditions. The effect appears on the first trial. Therefore, it must be attributed to the decay of a drive-like process, and not to a change in the incentive value of ICS.

When rewarded with intracranial stimulation (ICS) in a runway, rats perform better on massed trials than on spaced trials (Seward, Uyeda, \& Olds, 1960), whereas trial spacing has no effect when natural rewards are used (Cotton \& Lewis, 1957). Gallistel (1964) attributed this to the drive decay effect postulated by Deutsch (1960). Others have attributed this or related phenomena to a change in the incentive value of ICS (Seward et al, 1960), or to the unusual circumstances accompanying ICS reward (Gibson, Reid, \& Porter, 1965; Pliskoff, Wright, \& Hawkins, 1965). The following experiment was designed to decide among these alternatives.

Mothad

The experiment employed a $6 \mathrm{ft}$ runway with an 8 in. start area closed off by a solenoid operated door. Running times were recorded in 0.1 sec Intervals from a clock that started when the door dropped and stopped when the $S s$ interrupted a light beam 5-1/2 in. from the goal.

Mounted on the wall at the goal end of the runway were a $T$ shaped lever and a drinking tube. The drinking tube projected through a movable plastic shield connected to a solenoid that pulled against a spring. When extended by the spring, the shield barred access to the tube.

The Ss were 16 male white rats of the SpragueDawley strain, 110-160 days old. Eight of them were implanted with monopolar electrodes aimed at self stimulation sites along the medial forebrain bundle from the diagonal band of Broca to the ventral tegmental nucleus of Tsai. These elght were selected from an original group of 15 similarly implanted because they learned during initial training to press the goal lever for ICS in three $45 \mathrm{~min}$ dally sessions. Each lever press delivered a .32 sec tratn of monophasic negative going pulses. The pulse width was $.1 \mathrm{msec}$; frequency, 200 pulses/sec. For each rat the current intensity was adjusted to that level which maximized the rate of responding. The currents used ranged from $200 \mu \mathrm{A}$ to $700 \mu \mathrm{A}$. The current levels established at this time were used throughout the subsequent runway training.
Four days before testing began, the eight remaining rats had been placed on a deprivation schedule which gave them access to water for $15 \mathrm{~min}$ every $24 \mathrm{~h}$. These eight were selected from an original group of 10 because they learned during initial training to drink steadily from the drinking apparatus at the goal in three $45 \mathrm{~min}$ daily sessions. Each time the rat began drinking, a drinkometer triggered a timer which released the plastic shield after $45 \mathrm{sec}$. The shield sprang out, pushing the rat away from the tube and preventing access to it until the solenoid retracted the shield .50 sec later.

After three days of initial training half of each group began runway training with a 5 sec intertrial interval; the other half began with a $60 \mathrm{sec}$ interval.

There were 20 trials (runs) a day in the runway. Every day, before his first run, the rat was placed in the goal end of the runway and allowed 12 lever presses for ICS or 12 bouts of drinking. These 12 rewards were necessary to eliminate warm up effects, which are otherwise prominent in ICS rewarded performance. After the 12th warm up reward, the rats running on a $5 \mathrm{sec}$ interval were placed immediately in the start area. A timer released the start door 5 sec after the last reward. The rats running on a 60 sec interval were removed to a waiting cage for $55 \mathrm{sec}$ and then placed in the start area. The door opened 60 sec after the last reward. Each run was rewarded by three bouts of drinking or three lever presses for ICS.

For each rat, the interval between the last reward and the start of the next trial remained unchanged untll there had been no improvement in performance for five days. (To assess improvement, each day's results were tested against the best previous results using an $F$ test and a $p<.01$ criterion.) At the next session, the interval betwoen the last warm up reward and the first run was changed-from 5 to $60 \mathrm{sec}$ or from 60 to $5 \mathrm{sec}$. The rat was run for five days (100 trials) on this new intertrial interval.

\section{Results}

The results averaged over each group are presented in Fig. 1. A repeated measures analysis of variance yields an $F=14.50$ ( $p<.01)$ for the interaction between interval and type of reward. Individual results are: Seven out of 8 ICS Sa showed their group effect, as did 5 of 8 water rewarded $\mathrm{Ss}$ ( $p<.01$ for each S). Two water rewarded Ss showed an effect opposite their group effect $(p<.01)$. One $S$ in each group showed no effect $(p>.10)$.

For all seven ICS rewarded rats whose running speeds were affected by the intertrial interval, the 


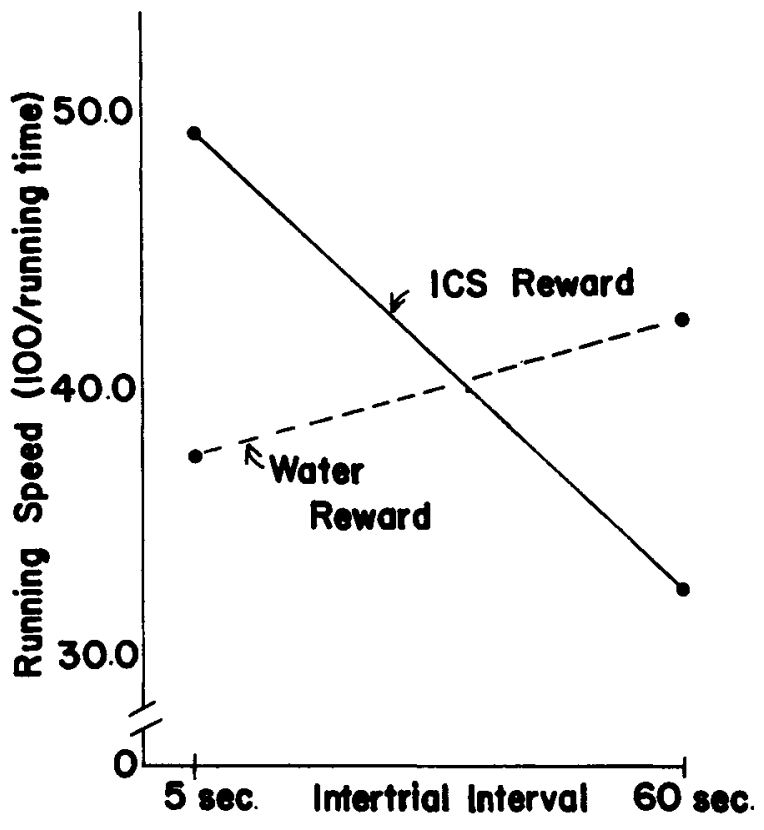

Fig. 1. Running speed as a function of intertrial interval and type of reward. Each point is an average of the mean performances of eight rats.

shift in running speed appeared on the first trial after the change in interval. Expressing each first trial speed as a $\mathrm{z}$ score on the distribution of the 100 trials immediately preceding the shift gives a probability score. The seven probabilities thus obtained combine (Winer, 1962 , p. 44) to yield a $X^{2}=72.66(d f=14, p<.005)$ for the assertion that, for the population of rats who show the effect at all, the effect is present before the rat has received a reward under the new conditions. Discussion

This last finding eliminates the possibility that the unusual effect of intertrial interval on ICS rewarded performance results from a change in the incentive value of ICS: The effect appears after the change in interval but before the rat has received a reward under the new conditions.
Also to be noted is the fact that the measured responses were identical under the two reward conditions. The conditions of reinforcement were similar in that the water reward was short, had an aversive component, and came as an immediate consequence of the terminal act (tube licking). The ICS reward was, if anything, larger than the water reward: At least, the average running speed of the ICS rewarded Ss was faster $(p>.10)$.

Finally, the running speeds of ICS rewarded Ss were faster at the shorter interval regardless of the original training interval and despite the fact that the Ss were trained to asymptote. Nor is the effect confined to a single electrode locus. Histology confirmed that the placements used here ranged the length of the medial forebrain bundle.

These results show that rewarding ICS has another property-one that does not derive from its rewarding properties but does influence how well a rat will perform for an ICS reward. This other property of ICS may be called a drive effect or drive-like effect insofar as one uses "drive" to denote whatever produces changes in the direction and avidity of behavior in the absence of changes in the animal's knowledge of the reward contingencies.

\section{References}

COTTON, J. W., \& LEWIS, D. J. The effect of intertrial interval on the acquisition and extinction of a running response. J. exp. Psychol. 1957, 54, 15-20.

DEUTSCH, J. A. The structural basis of behavior. Chicago: Chisago University Press, 1960.

GALLISTEL, C. R. Self-stimulation and its theoretical implications. Psychol. Bull, 1964, 61, 23-34.

GIBSON, W. E., REID, L. D., \& PORTER, P. B. Intracranial reinforcement compared with sugar-water reinforcement. Science, 1965, 148, 1357-1359.

PLISKOFF, S. S., WRIGHT, J. E., \& HAWKINS, T. D. Brain stimulation as a reinforcer: intermittent schedules. J. exp. Anal. Behav., 1965, 8, 75-88.

SEWARD, J. P., UYEDA, A. A., \& OLDS, J. Reinforcing effect of brain stimulation on runway performance as a function of interval between trials. J. comp. physiol Psychol, 1960, 53, 224-228.

WINER, B. J. Statistical principles in experimental design. New York: MoGraw-Hill, 1962. 